\title{
Simulated chorus attracts conspecific and heterospecific Amazonian explosive breeding frogs
}

\author{
Fouquet Antoine ${ }^{1,{ }^{*}}$, Tilly Thomas ${ }^{2}$, Pašukonis Andrius ${ }^{3}$, Courtois Elodie A. ${ }^{4}$, Gaucher Philippe ${ }^{4}$, \\ Ulloa Juan ${ }^{5,6,7}$, Sueur Jérôme ${ }^{5}$
}

${ }^{1}$ Laboratoire Evolution et Diversité Biologique (EDB) UMR5174 Toulouse, France

2 Studio d'en haut Nantes, France

${ }^{3}$ Department of Biology Stanford University Stanford CA, USA

${ }^{4}$ Laboratoire Ecologie, Evolution, Interactions des Systèmes Amazoniens (LEEISA) Cayenne ,French Guiana

5 Institut Systématique Evolution Biodiversité (ISYEB) Muséum National d'Histoire Naturelle CNRS

Sorbonne Université EPHE Paris ,France

${ }^{6}$ Equipe Communications Acoustiques UMR 9197 Neuro-PSI-CNRS Université Paris-Sud

Orsay ,France

7 Instituto de Investigación de Recursos Biológicos Alexander von Humboldt Bogotá ,Colombia

* Corresponding author : Antoine Fouquet, email address : fouquet.antoine@gmail.com

\begin{abstract}
:
In tropical regions, some anuran species breed "explosively", reproducing in massive and highly diverse aggregations during a brief window of time. These aggregations can serve as acoustic beacons, attracting other anurans toward seasonal ponds. We hypothesize that conspecific and heterospecific calls play a role in navigation toward ponds and synchronization of reproduction among species. We simulated a chorus of two species (Trachycephalus coriaceus and Chiasmocleis shudikarensis) with contrasting call characteristics (low-frequency vs. high-frequency) and reproductive strategies (strict pond breeder vs. opportunistic) near known explosive breeding sites. We predicted that choruses of $\mathrm{T}$. coriaceus are more attractive to heterospecifics than of $\mathrm{C}$. shudikarensis because the first provides a more reliable indicator of a suitable breeding pond and a better long-distance signal. We found that both choruses attracted conspecific frogs to the playback outside a natural breeding event. As predicted, heterospecifics were attracted only by low-frequency calls of $\mathrm{T}$. coriaceus that breeds exclusively in large ponds, but not by higher frequency calls of $\mathrm{C}$. shudikarensis that also breeds in small pools not suitable for other species. Our study presents the first experimental evidence that tropical explosive breeding anurans are attracted to conspecific and heterospecific choruses. The contrasting effect of the playback of the two species on heterospecifics suggests that the attractive effect of a chorus depends on the reproductive strategy of both the sender and the receiver. Given the abundance and diversity of communities in tropical ecosystems, the use of heterospecific acoustic cues may prove widespread and requires further investigation. Abstract in Portuguese is available with online material.
\end{abstract}

Keywords : Anuran, French Guiana, Neotropics, orientation, phonotaxis, reproduction 


\section{INTRODUCTION}

Social information obtained from conspecifics, and sometimes from heterospecifics, can be used by animals to assess the presence of resources or threats (Danchin et al. 2004; Goodale et al. 2010). Animals forming mixed-species breeding aggregations, such as some birds (Monkkonen et al. 1999; Thomson et al. 2003; Mukhin et al. 2004), mammals (McGuire et al. 2009; Forsman et al. 2012) and amphibians (Diego-Rasilla \& Luengo 2004, 2007; Pupin et al. 2007; Madden \& Jehle 2017) can rely on the presence of others that share their habitat requirements to orientate themselves towards these habitats and the information they use can be acoustic (e.g. Magrath et al. 2005; Phelps et al. 2007).

Most anuran amphibians (i.e., frogs and toads) need water for breeding, and the ability to orientate and migrate toward aquatic sites is crucial for survival and reproduction (Wells 2007; Pittman et al. 2014; Sinsch 2014; Joly 2019). Depending on species and the context, amphibians can use acoustic, magnetic, mechanical, olfactory, and visual directional information (for reviews see Ferguson 1971; Sinsch 1990; 2006). Natal imprinting and spatial memory play a crucial role when returning to known oviposition sites (e.g., Heusser 1960; Shoop 1965; Ishii et al. 1995;

Pašukonis et al. 2016), but social cues are also particularly important when locating new resources, facilitating orientation, and synchronizing breeding activity (e.g., Stamps 1988; Reed et al. 1993; Seppänen et al. 2007; Buxton et al. 2015; 2018; James et al. 2015). Acoustic communication, in particular, plays a key role in the reproductive biology of anuran amphibians (Gerhardt \& Huber 2002), and male choruses could represent a cue indicating suitable breeding habitat.

Despite the fact that most amphibians occur in the tropics (Jenkins et al. 2013), experimental studies on cues guiding amphibians to breeding ponds remains limited to only a few temperate-region species. These studies have shown that some but not all anurans are attracted to 
conspecific chorus (e.g., Gerhardt \& Klump 1988; Ryan et al. 1981; Wollerman 2002; Bee 2007; Swanson et al. 2007; Christie et al. 2010; Buxton et al. 2015; 2018; James et al. 2015; Chang et al. 2018). Current evidence suggests that species which depend on unpredictable seasonal ponds are more attracted to conspecific playback than species that rely on stable, permanent ponds (Gerhardt \& Klum 1988; Buxton et al. 2015; 2018 but see Swanson et al. 2007). In addition, acoustic cues of sympatric anurans might be used by newts to orientate toward shared breeding sites (Diego-Rasilla \& Luengo 2004, 2007; Pupin et al. 2007; Madden \& Jehle 2017 but see Slabbekoorn \& Bouton 2008). Such heterospecific phonotaxis has also been suggested for anurans although direct evidence remains limited, especially under natural conditions (Oldham \& Gerhardt 1975, Gerhardt \& Klump 1988; Ryan \& Rand 1993, Bernal et al. 2007). Chang et al. (2018) recently used a naturalistic setup to demonstrate that males of a tropical treefrog (Rhacophorus prasinatus) approach a chorus of some heterospecific frogs but ignore other sympatric species. Such selective use of heterospecific cues may reflect cost/benefit trade-offs of interspecific interaction requiring further investigation.

Some anuran species 'explosively breed' (sensu Wells 1977), aggregating in groups numbering hundreds to thousands of individuals and call during a narrow time window of just a few hours or days per breeding season. An explosive breeding strategy may be beneficial, by diluting the predation risk for adults, eggs, and larvae and increase mate attraction (Ryan et al. 1981; Gerhardt \& Huber 2002). In tropical regions such as Amazonia, anuran explosive breeding generally involves highly-diverse communities with sometimes more than ten species breeding simultaneously (Aichinger 1987; Hödl 1990; Gottsberger \& Gruber 2004; Prado et al. 2005; Ulloa et al. 2019). Such phenomena typically occur in ephemeral sparsely distributed ponds (Rodrigues et al. 2010) that dry out during periods of low precipitation and thus have relatively few aquatic predators when ponds fill up during the rainy reason. Explosive breeding events are so localized, brief and synchronized that the yet largely unknown cues triggering these events 
101 must be spatiotemporally unequivocal across species. Ulloa et al. (2019) found that rainfall

102 during the previous 48 hours was the most important factor predicting explosive breeding events

103 in French Guiana, which could also trigger the long distance migration of individuals with

104 previous experience of the breeding sites. However, such environmental triggers are unlikely to

105 explain how dispersers locate new distant breeding sites and how they synchronize their

106 migration for arrival into the pond. The acoustic intensity of the choruses can reach $100 \mathrm{~dB}$ SPL

107 measured in the middle of the aggregation and can be heard several hundreds of meters away.

108 We, therefore, hypothesize that intense chorus sound is used by tropical explosive breeding

109 species to both synchronize breeding among species and to orientate toward breeding sites.

110 To test if calls of explosively breeding frogs are attractive to both conspecifics and

111 heterospecifics, we carried out a field playback experiment near known explosive breeding sites

112 in the Amazonian rainforest of French Guiana. We specifically tested whether the chorus

113 produced by two common explosive breeder species with divergent call characteristics and life-

114 histories can attract conspecifics and heterospecifics outside a natural explosive breeding event.

115 The first species, Trachycephalus coriaceus, is a large arboreal frog that breeds exclusively in

116 large ephemeral ponds that are suitable for numerous other species of explosive breeders. Thus, $T$.

117 coriaceus calls may be used as a reliable acoustic cue indicating suitable breeding habitat by

118 other species. The second species, Chiasmocleis shudikarensis is a small terrestrial frog that also

119 uses smaller ephemeral ponds not suitable for other species. Thus, their calls may not be a

120 reliable cue for heterospecifics. If explosive breeders are selectively using social information,

121 then we predict $T$. coriaceus choruses to attract both heterospecifics and conspecifics, and $C$.

122 shudikarensis choruses to only attract conspecifics. 


\subsection{Study site}

127

128 Experiments were carried out in three temporary ponds in French Guiana, along the Kaw

129 Mountain $\left(4^{\circ} 36^{\prime} \mathrm{N} ; 52^{\circ} 16^{\prime} \mathrm{W}\right)$ where explosive breeding events have been irregularly surveyed for

130 the last 15 years (Figure 1A). The climate is characterized by two periods of rainfall: the small

131 rainy season takes place from early December to the end of February while the main rainy season

132 occurs from April to July. Temporary shallow water bodies, or ponds, are flooded during the rainy

133 seasons and then dry out during periods of low rainfall. The study sites corresponded to three

134 temporary ponds named "Blanc", "Arlesienne" and "Caiman". These ponds are surrounded by

135 dense tropical forest, located between 236 and $313 \mathrm{~m}$ above sea level, covering an area of 399.5

$136 \mathrm{~m}^{2}, 672.0 \mathrm{~m}^{2}$ and $1192.3 \mathrm{~m}^{2}$ respectively.

137

\subsection{Playback experiment}

139

140 Four diamond-shaped pitfall stations were deployed at the onset of the rainy season 40 m away

141 from each pond (Figure 1B). Fourteen litre buckets linked with $70 \mathrm{~cm}$ high plastic tarp fences

142 were used to trap anurans. Three out of four of pitfall stations were equipped with a speaker (Fun

143 Generation PL 108 A) powered by a generator (Honda EU1000i operating at $50 \mathrm{~dB}$ A) placed

144 near the pond i.e. at a similar distance from all the pitfall stations. The fourth pitfall station was

145 used as a silent control to estimate the number of anurans captured accidentally in the area.

146 We used three different playback stimuli: (1) Chiasmocleis shudikarensis, (2)

147 Trachycephalus coriaceus, and (3) pink noise - a random noise having equal energy per octave

148 similar to the background noise of rainfall (Figure 2). These stimuli were built using Logic pro

149 one (Apple inc.). Chiasmocleis shudikarensis emits a continuous series of multipulsed notes (17

150 fused pulses per note) of 0.095-0.099 $\mathrm{s}$ in duration and spaced by $0.065-0.010 \mathrm{~s}$ pauses. The 
151 fundamental frequency $(f 0)$ is at about $1.6 \mathrm{kHz}$ with a positive frequency modulation of about 0.5

$152 \mathrm{kHz}$ from the beginning to the end of each note. The dominant frequency, which corresponds to

153 the second harmonic (2f0), is at about 3.5-3.6 kHz. The C. shudikarensis stimulus consisted of a

$15442 \mathrm{~s}$ recording of an isolated individual of C. shudikarensis (Marty \& Gaucher 1999), copied 100

155 times within a single track, each copy being successively time-shifted of $0.5 \mathrm{~s}$ (Fig. 2B).

156 Trachycephalus coriaceus emits long moans of $0.9-1 \mathrm{~s}$ in duration irregularly spaced every

157 second or so. These calls are trains of pulses $(60 / \mathrm{s})$ with a fundamental frequency $(f 0)$ around

$158 \quad 0.35 \mathrm{kHz}$. The fundamental frequency is the dominant frequency (Fig. 2A). The T. coriaceus

159 stimulus consisted of a $52 \mathrm{~s}$ recording of a chorus of five individuals of $T$. coriaceus (recorded by

160 Thomas Tilly), copied five times within a single track, each copy being successively time-shifted

161 being successively time-shifted of $0.5 \mathrm{~s}$ (Fig. 2B). For this track, sounds of frequency above 1

$162 \mathrm{kHz}$, corresponding to other surrounding species, were removed using a high-pass filter. The time

163 shifting process produces a continuous chorus of overlapping calls that mimics a chorus

164 sequence, and the number of overlapping tracks approximates the abundance of individuals

165 generally observed in the ponds ( $\sim 100$ C. shudikarensis and $\sim 25$ T. coriaceus $)$. The pink noise

166 was generated by an internal function generator of LogicPro (Fig. 2B). These sequences were

167 looped in order to last the duration of the playback. All sounds had a sampling frequency of 44.1

$168 \mathrm{kHz}$ and digitization depth of 16 bits.

169 The playbacks were carried out simultaneously for six successive nights at each pond

170 from 2 to 7 December 2018, seven days after the reproduction of the explosive breeding species.

171 Each station was playing one of the three stimuli between $1900 \mathrm{~h}$ and $2200 \mathrm{~h}$. No specimens were

172 found in the pitfalls before each playback. The acoustic level (peak measurement) of the

173 playbacks was measured at a $1 \mathrm{~m}$ distance from the speaker at waist height. The level was set at

$17495 \mathrm{~dB}$ SPL at $1 \mathrm{~m}$, which corresponded to measurements taken in the same ponds during previous

175 explosive breeding events (AF personal observation). To avoid any spatial habituation, the three 
stimulus tracks were rotated clockwise between the pitfall stations each night. After $1 \mathrm{~h} 30$ of playback (that is, at $2030 \mathrm{~h}$ ), all frogs were counted in the pitfalls, in the trees surrounding each station within the limit of the plastic tarp fences, and on the ground within the same limits $(4.5 \mathrm{~m}$ radius $=\sim 60 \mathrm{~m}^{2}$ ). A second count was made at the end of the playback session (that is, at $2200 \mathrm{~h}$ ). Because counted individuals were neither caught nor marked during the playback, only the results of one counting session (that with the highest number of individual frog counts) was used for the analysis. For the same reason the sex of the individuals could not be recorded. The animals were released near the pond, about $5 \mathrm{~m}$ away from the fence at the end of the playback. One speaker of the "Blanc" pond failed to play back the pink noise before the second night. No calling activity of the observed species was heard during the experiment.

\subsection{Data analysis}

A generalized linear mixed-effects model (GLMM) was used to test whether the number of individuals found around the playback speaker was influenced by the acoustic stimuli. The number of individuals was combined over the three ponds and included individuals found in ground pitfalls (terrestrial species) and on tree branches (arboreal species). The model included the acoustic stimuli and the species as fixed effects, and date and pond as random effects. The model was fitted in R (R core Team 2019) using the function glmer of the R-package lme4 (Bates et al. 2014). Since the response variable is a count variable, a Poisson GLMM was first fitted, but the dispersion statistic of the fitted model indicated a slight overdispersion (c-hat=2.67). Hence, the next model in complexity was fitted with a negative binomial GLMM (Lindén and Mäntyniemi 2011). The Akaike information criterion (AIC; Akaike 1973) computed on both models (the Poisson and the negative binomial models), indicated that the negative binomial model was more suitable. Model stability was checked by excluding ponds and dates, one at a 
time, from the data. This check did not indicate any influential ponds or dates. Variance Inflation

202 Factors were derived using the function vif of the R-package car (Fox \& Weisberg 2011). When applied to a standard generalized linear model excluding the random effects, it did not indicate collinearity to be an issue. The fitted model was not zero-inflated as revealed with the function ‘testZeroInflation' from the R-package DHARMa (Hartig 2017). The full model was compared with the null model (including only the species and the random effects, pond and date) with a likelihood ratio test using the base $\mathrm{R}$ function 'anova', with argument test set to 'Chisq'. To compare the counts of each species, two additional models were fitted, one for $C$. shudikarensis and one for T. coriaceus. Since the counts for O. leprieurii were zero on three of the four experiments, no model was fitted for this species. As for the previous analysis, model stability and the absence of zero inflation were checked. Then, a Tukey test was performed as a post-hoc procedure to examine pairwise comparisons for each species between treatments. The post-hoc test was computed with the function 'glht' from the R package multicomp (Hothorn et al. 214 2008). https://doi.org/10.5061/dryad.8w9ghx3jr.

\section{RESULTS}

We observed a total of fourteen species around the playback stations. Among these fourteen species, six were explosive breeding species (see below), five were prolonged arboreal breeding species (Dendropsophus minutus, D. sp. 1, Callimedusa tomopterna, Phyllomedusa vaillanti, Scinax sp. 2) and four were terrestrial breeding species (Adenomera andreae, Rhinella castaneotica, Leptodactylus mystaceus). Out of these fourteen species, only six were detected in the pitfalls (Chiasmocleis shudikarensis, Trachycephalus coriaceus, Osteocephalus leprieurii, $R$. 
castaneotica, Ceratophrys cornuta, A. andreae). Among the explosive breeding species, half were detected in too low numbers ( $<6$ individuals) to draw any conclusion $(O$. taurinus, $C$. cornuta, Scinax sp. 3). However, males and females belonging to three species (C. shudikarensis, T. coriaceus and $O$. leprieurii) were found frequently at playback stations. None were observed calling, but T. coriaceus were observed in amplexus on two occasions, and O. leprieurii on one 231 occasion.

Overall, the full GLMM was significant compared to the null model $\left(\chi^{2}=49.71, d f=3\right.$, $\mathrm{p}<0.001$ ), revealing that there was a clear effect of the acoustic stimuli and species on the probability of attracting individuals using the playback. More specifically, the stimulus " $T$. coriaceus" had the stronger effect in attracting individuals when compared with the other stimuli. The stimuli "C. shudikarensis" and pink noise also had a positive effect of attracting individuals, however the pink noise stimulus was not significant (Table 2). Post-hoc test on the species C. shudikarensis revealed significant differences between the silent and the "C. shudikarensis" stimuli $(\mathrm{x}=1.3218, \mathrm{p}<0.01)$, and between the silent and " $T$. coriaceus" stimuli $(\mathrm{x}=1.1802, \mathrm{p}=0.032)$. Differences between the silent and pink stimuli were not significant. For the species T. coriaceus, the post-hoc test revealed a significant difference 242 between the silent and "T. coriaceus" stimuli $(\mathrm{x}=4.2195, \mathrm{p}<0.001)$ and between the pink and the "T. coriaceus" stimuli $(\mathrm{x}=2.5078, \mathrm{p}<0.001)$. "C. shudikarensis" stimulus for $T$. coriaceus was not 244 analyzed statistically since it only had zero values. It is noteworthy that $O$. leprieurii were only 245 found with the "T. coriaceus" playback. Osteocephalus taurinus, Ceratophrys cornuta and Scinax 246 sp. 3 was also attracted by the "T. coriaceus" track and the pink noise and but unfrequently and in 247 low numbers. 
251 Our study presents the first experimental evidence that tropical explosive breeding anurans are

252 attracted to conspecific and heterospecific choruses. As expected, males and females of

253 Chiasmocleis shudikarensis and Trachycephalus coriaceus were attracted to conspecific calls.

254 Moreover, the call of T. coriaceus also attracted heterospecific C. shudikarensis and

255 Osteocephalus leprieurii as well as other species in low numbers. The traps used were not set

256 within natural breeding sites but were still effective at attracting a number of explosive breeding

257 anuran species, suggesting that explosive breeders use heterospecific calls to locate new breeding

258 sites and synchronize their reproduction.

A variety of animals use heterospecific cues and signals as 'public information', through

260 which they are able to assess the presence of resources or potential risks (Goodale et al. 2010).

261 For example, male túngara frogs, Engystomops pustulosus, adjust their calling behaviour to the

262 calls of other species - probably as an indicator of predation risk (Phelps et al. 2007). Many

263 migrating species rely on the presence of heterospecifics that share their habitat requirements to

264 orientate themselves towards these habitats, a pattern that occurs in marine crustaceans (Stanley

265 et al. 2012), marine molluscs (Lillis et al. 2013), marine fish (Simpson et al. 2005), birds

266 (Mukhin et al. 2004; Thomson et al. 2004), frogs (Chang et al. 2018) and newts (Diego-Rasilla \&

267 Luengo 2004; Pupin et al. 2007, Madden \& Jehle 2017). Our study suggests that such 'public

268 information' produced by male mating calls may also play a role in the breeding ecology of

269 tropical explosively breeding frogs.

As predicted, only the vocalization of Trachycephalus coriaceus, but not those of

271 Chiasmocleis shudikarensis, attracted other species. Being an exclusively explosive breeder and

272 arboreal, T. coriaceus might be able to detect the accumulation of water faster than other species

273 and trigger the migration of other conspecifics and heterospecifics toward ponds of sufficient

274 size. Individuals of $T$. coriaceus were observed at the speaker only a few minutes after the start of

275 the playback, even though the natural explosive breeding had occurred days before the 
experiment. This observation suggests high mobility and opportunistic readiness of this species to reproduce. The call of $T$. coriaceus is also notably lower in frequency compared to other explosive breeding species (Ulloa et al. 2019). Low frequency sounds propagate further than higher frequency sounds in dense habitats (Larsen \& Radford 2018), making the calls of $T$. coriaceus a more suitable long-distance cue for other species. In contrast, the calls of $C$.

281 shudikarensis did not attract heterospecific frogs suggesting that this species does not play a role 282 in the emergence of explosive breeding events. The call of this species might not be a reliable cue since C. shudikarensis is a small-bodied opportunistic breeder that also calls from small puddles that are not suitable for larger species. The differential effects of the calls of these two species on heterospecifics suggests that the attractive effect of a chorus depends both on the reproductive strategy of the sender and the receiver, as recently shown in another tropical treefrog (Chang et al. 2018). Nevertheless, an experiment in a controlled environment would be needed to tease apart detectability and ecological relevance of heterospecific cues.

The anuran peripheral auditory system display enhanced sensitivity to frequency range of conspecific calls (Simmons 2013). Tuning of the auditory perception is particularly expected in

291 environments with high levels of social background noise, the "cocktail party problem", such as 292 those experienced by explosive breeding frogs (Velez et al. 2013). In the absence of data on the auditory perception of the species involved in our experimentation, we cannot rule out that the

294 higher frequency of the $C$. shudikarensis stimulus $(3.6 \mathrm{kHz})$ was simply not perceived by

295 Trachycephalus coriaceus and Osteocephalus leprieurii which emit lower dominant frequencies 296 about 0.3 and $1.6 \mathrm{kHz}$ respectively. Nevertheless, even if tuned toward conspecific frequency, 297 frogs most likely remain able to perceive a wide bandwidth from their environment such as rain 298 and fire (Grafe et al. 2002, Penna et al. 2005) but also heterospecific individuals (Gerhardt \& 299 Schwartz 1995). 
Suitable breeding sites are often patchy and limited for anuran species, and several studies

301 have demonstrated that conspecific choruses allow frogs to locate ponds (e.g. Gerhardt \& Klump

common in the tropics, heterospecific calls could often be used as indicators of suitable breeding sites. Moreover, the calls of the species in the explosive breeding community vary greatly in call intensity. Some species produce relatively loud calls (e.g., C. cornuta, T. coriaceus) but other, such as $O$. leprieurii and Scinax spp., individually call at much lower intensities. The ability of the later to use loud heterospecific calls may allow them to find breeding sites and provide a timing cue without having to invest energy and exposing themselves to the risks related to loud 311 conspicuous calls. In this context, lower intensity calls may have either been selected for heterospecific phonotaxis, or were the consequence of selection for minimizing energy species rely on the calls of only a few species (such as T. coriaceus) to find suitable breeding

315 sites, then this would also suggest they could represent keystone species for the explosive 316 breeding community. Anurans with prolonged breeding seasons typically face strong competition for food 318 availability, calling territories, oviposition sites, and acoustic space with conspecifics and 319 heterospecifics (Robertson 1986; Wogel et al. 2006; Wells 2007; Amézquita et al. 2011; Chang et 320 al. 2018). These species show a variety of derived reproductive strategies, such as terrestrial 321 oviposition and parental care, and males may avoid overcrowded breeding sites investing instead 322 in searching for suitable long-term territories (Wells 1977; Duellman \& Trueb 1994; Wells 2007). 323 In contrast, explosive breeding events occur very rapidly and gather multiple species, all 324 depositing eggs directly in the water suggesting limited competition for food, territory, 
oviposition sites, and acoustic space; the benefits seem to outweigh the cost of intra- and interspecific competition. Competition among larvae is poorly understood, but distinct ecomorphological guilds (e.g. suspension feeder, nektonic, benthic) (Altig \& Johnston 1989; Schulze et al. 2015) and niche partitioning might limit competition among heterospecific larvae (Inger et al. 1986; Alford 1999). Moreover, the benefits of explosive breeding system have been claimed to depend on the dilution effect toward predators favouring large aggregations (Wrona $\&$ Dixon 1991). Explosive breeding is thus particularly favourable to the emergence of heterospecific interactions. Heterospecific audiences could be beneficial to loud callers because the increased number of individuals decreases the predation risk per individual. Therefore, the trade-off between increased competition and the predator dilution effect might favour the coevolution of heterospecific eavesdropping in explosive breeders.

Heterospecific eavesdropping is widespread across animals (Goodale et al. 2010), but the empirical evidence of acoustic interactions among amphibian species is scarce and limited to prolonged breeders and species assemblages with low diversity (e.g. Diego-Rasilla \& Luengo 2004, 2007; Pupin et al. 2007; Madden \& Jehle 2017; Chang et al. 2018). Our study shows that tropical explosive breeding anurans are attracted to heterospecific acoustic signals that indicate a potential breeding opportunity, which is extremely circumscribed in space and time. Given the abundance and diversity of communities in tropical ecosystems, the use of heterospecific acoustic cues could prove to be widespread and requires further investigation. Moreover, the use of conspecific signals to attract animals to suitable habitats is a management strategy used for birds and frogs (Buxton et al. 2015; 2018). Our results suggest that in tropical systems, playbacks of the calls of certain species could be used in a conservation context at a community scale. 
348 Table 1: Mean number of individuals per stimulus (C. shudikarensis, T. coriaceus, pink noise,

349 silent) averaged over six nights, and over the three ponds. The three most abundant species are

350 underlined in grey, and the explosive breeding species are in bold (the other ones are prolonged

351 breeder; A. andreae and R. castaneotica do not breed in the pond).

352

Mean number of individuals per night/pond

Stimulus C. shudikarensis T. coriaceus Pink Silent Total

$\begin{array}{lllllc}\text { C. } \text { shudikarensis } & 3.1 & 2.4 & 2.3 & 0.8 & 143 \\ \text { T. coriaceus } & 0.0 & 3.8 & 0.3 & 0.2 & 73 \\ \text { O. leprieurii } & 0.0 & 1.7 & 0.0 & 0.0 & 20 \\ \text { O. } \text { taurinus } & 0.0 & 0.3 & 0.3 & 0.0 & 5 \\ \text { C. cornuta } & 0.0 & 0.2 & 0.2 & 0.0 & 2 \\ \text { S. sp. 3 } & 0.0 & 0.2 & 0.0 & 0.0 & 1 \\ \text { S. sp. } 2 & 0.1 & 0.1 & 0.0 & 0.0 & 2 \\ \text { D. sp. } 1 & 0.0 & 0.0 & 0.0 & 0.1 & 1 \\ \text { D. minutus } & 0.1 & 0.1 & 0.0 & 0.2 & 6 \\ \text { L. mystaceus } & 0.0 & 0.0 & 0.0 & 0.3 & 5 \\ \text { P. vaillanti } & 0.1 & 0.0 & 0.0 & 0.1 & 3 \\ \text { C. tomopterna } & 0.2 & 0.2 & 0.1 & 0.0 & 8 \\ \text { R. castaneotica } & 0.1 & 0.1 & 0.0 & 0.0 & 2 \\ \text { A. andreae } & 0.0 & 0.0 & 0.1 & 0.0 & 1 \\ \text { Total } & 62 & 140 & 39 & 31 & 272\end{array}$


355 Table 2: Parameter estimates and 95\% confidence intervals for best fit model predicting number

356 of individuals found on the traps as a function of playback simuli in tropical explosive breeding

357 species. Parameter estimates are shown as differences with respect to the first category (Intercept)

358 in each variable (silent playback stimulus and species Chiasmocleis shudikarensis).

\begin{tabular}{lcccccc} 
Predictor & Estimate & Confidence intervals & z value & $\operatorname{Pr}(>|\mathbf{z}|)$ & \\
\hline (Intercept) & -0.67 & -1.64 & 0.30 & -1.345 & 0.1785 & \\
Osteocephalus leprieuri & -2.54 & -3.51 & -1.57 & -5.141 & $2.74 \mathrm{E}-07$ & $* * *$ \\
Trachycephalus coriaceus & -1.76 & -2.53 & -0.99 & -4.483 & $7.35 \mathrm{E}-06$ & $* * *$ \\
Stimulus Pink noise & 0.97 & -0.01 & 1.96 & 1.940 & 0.0523 & \\
Stimulus C. shudikarensis & 1.00 & 0.07 & 1.93 & 2.116 & $3.43 \mathrm{E}-02$ & $*$ \\
Stimulus T. coriaceus & 3.07 & 2.09 & 4.06 & 6.102 & $1.05 \mathrm{E}-09$ & $* * *$
\end{tabular}




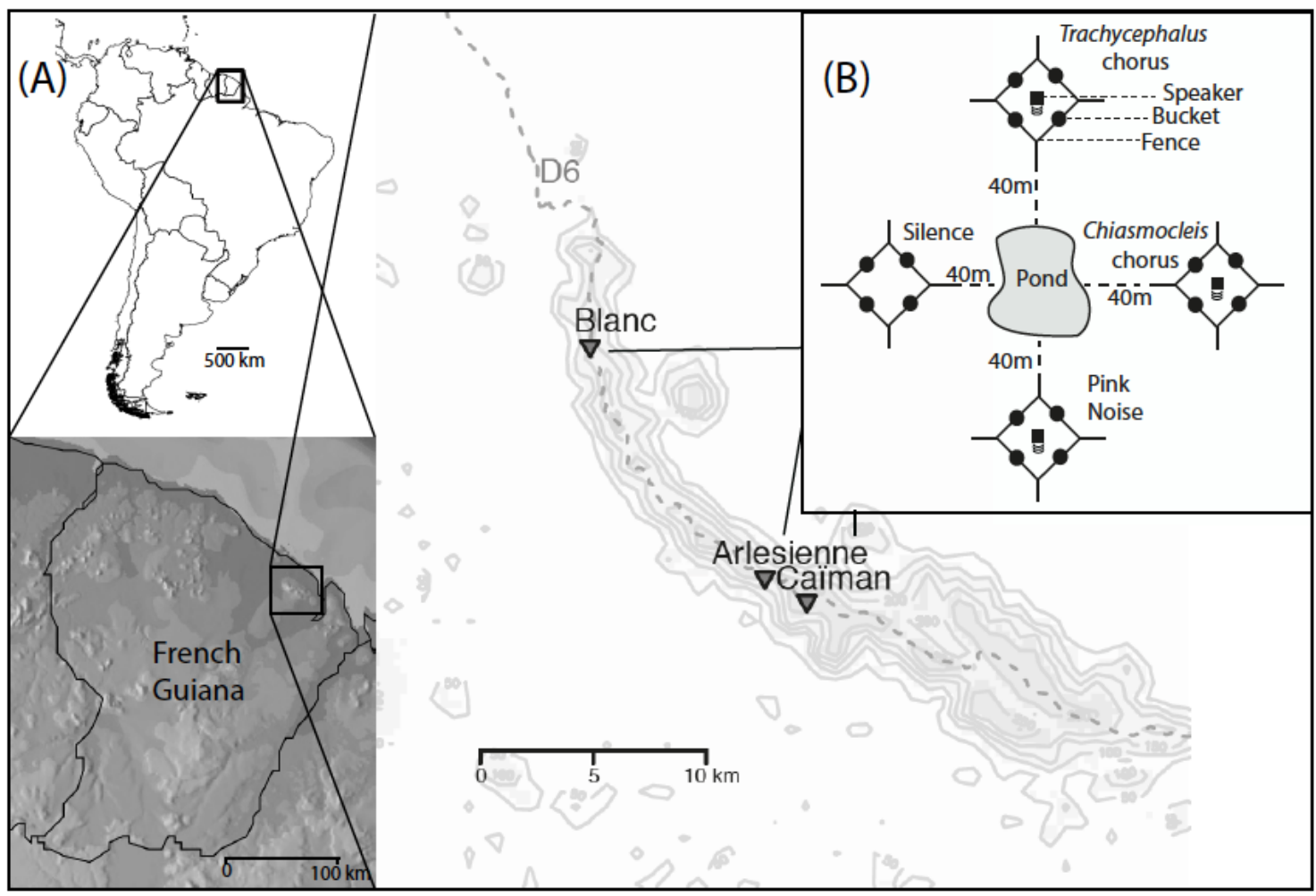

Figure 1

364 Site location and experimental setup. (A) Map of French Guiana and the Kaw Mountain with

365 the location of the three temporary ponds, the access road (D6 dotted grey line). (B) The diagram

366 of the experimental setup deployed at each pond depicting the four positions where acoustic

367 stimuli were played back. Each loudspeaker was surrounded by diamond-shaped fence and pitfall traps. 
(A)
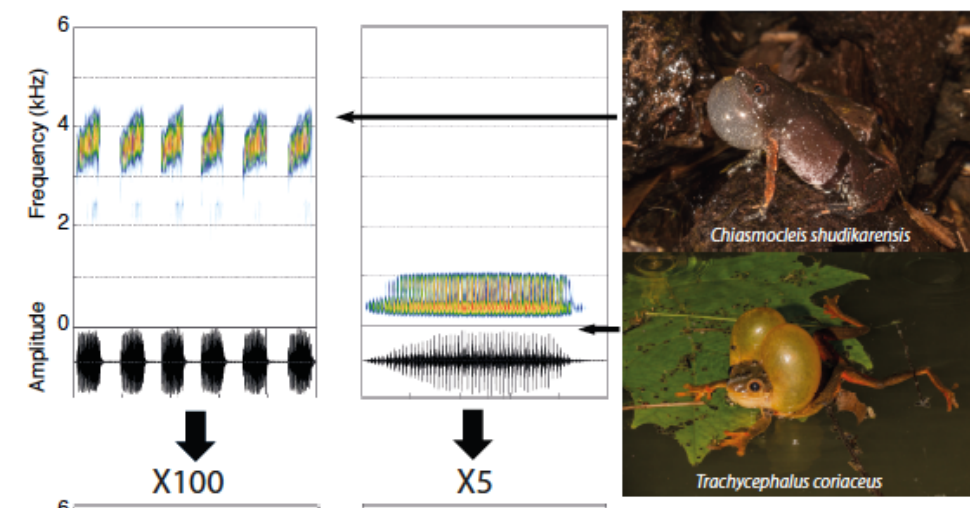

(B)
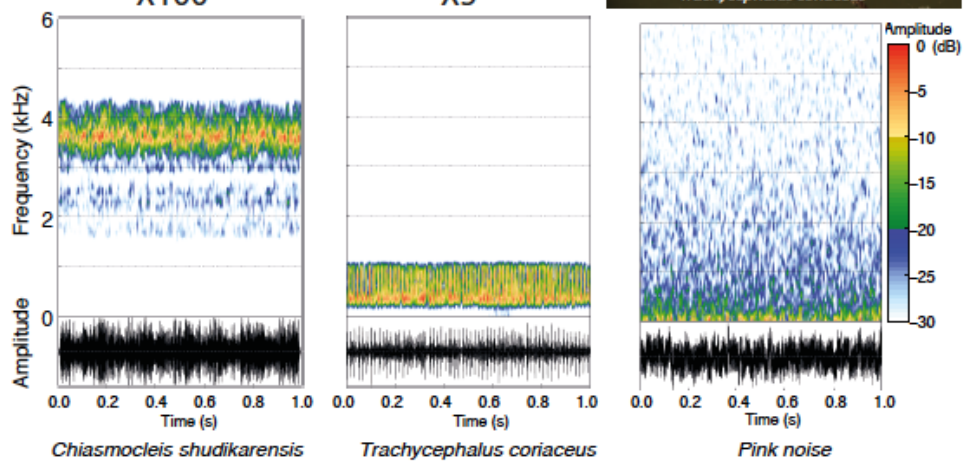

370 Figure 2 Acoustic stimuli. (A) One-second spectrograms and waveforms of the recordings used

371 to build the $C$. shudikarensis call and the T. coriaceus call signals after high-pass filtering. (B)

372 One-second spectrograms and waveforms of the generated stimuli mimicking choruses of $C$.

373 shudikarensis ( $\sim 100$ individuals) and T. coriaceus ( $\sim 25$ individuals) and the pink noise used in

374 the playback experiments. Short-term Fourier transform parameters: sampling frequency of 44.1

$375 \mathrm{kHz}$, Hanning window of 500 samples with an overlap of $90 \%, 30 \mathrm{~dB}$ dynamic range. Obtained

376 with Seewave R package (Sueur et al. 2008). Pictures show males of each species while calling.

377 Note the inflated vocal sacs. Pictures by Antoine Fouquet. 


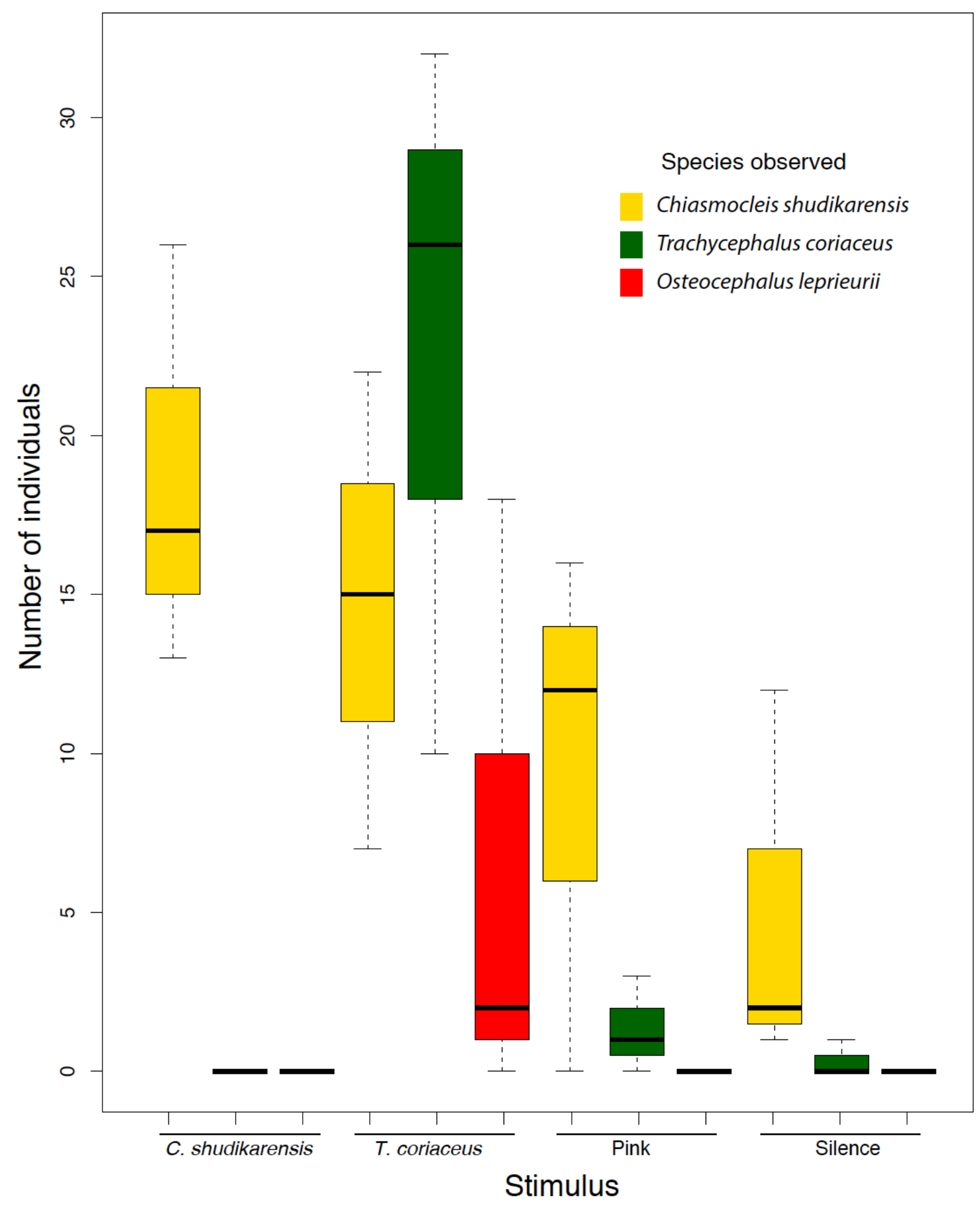

379 Figure 3 Boxplot of the mean number of individuals over the three ponds (summed for the 6

380 nights) of the most abundant species found with the four stimuli (C. shudikarensis, T. coriaceus,

381 pink noise and silent control). Note that Osteocephalus leprieurii is a species that does not breed 382 in the pond "Blanc". 
384 Acknowledgements We warmly thank the people who loaned some equipment, helped for the 385 set-up of the pitfalls and the survey: Vincent Rufray, Mael Dewynter, Amélie Beillard, Alexandra 386 Le Manchec, Morgane Sineau, Florie Delfour, Joris Grenon, Yvon Guenescheau, Bastien Moisan, 387 Martin Bonhomme, Lois Bouchet, Hugo Reizine, Laetitia Proux, Julien Clozeau, Pierre Leclerc, 388 Julien Morand, Anais Bonnefond, Benoit Villette, Elven Remerand, Timothée Lepape, Mathilde 389 Segers, Audric Broux, Vincent Premel, Bettina Lê, Sevahnee Pyneeandy, Yannick Lima, Michel 390 Blanc, Mathias Fernandez, IRD Cayenne, the GEPOG (Groupe d'Etude et de Protection des 391 Oiseaux de Guyane) and the CERATO herpetological society. We are grateful to the USR3456 392 LEEISA (Laboratoire Ecologie, Evolution, Interactions des Systèmes amazoniens) in Cayenne, 393 the Reserve Naturelle des Marais de Kaw-Roura (Jean Olivier and Yannick Lima), the DEAL 394 Guyane (the Direction de l'Environnement, de l'Aménagement et du Logement). We also thank Anthony Taillard, Pierre Judon, Jason lescalleet and Gildas houdebine for their contributions in the processing of the media related to the study and Julian Donald for proof-reading the English of this manuscript. We are grateful to two anonymous referees for their very helpful and constructive comments on the submitted manuscript.

Funding This study benefited from an "Investissement d'Avenir" grant managed by the Agence 401 Nationale de la Recherche (CEBA, ref. ANR-10-LABX-25-01).

402 Animal Welfare Note This study was approved by the "Direction de l'Environnement, de 403 l'Aménagement et du Logement de la Guyane" (arrêté prefectoral R03_2018_10_25_002) 404 following the positive recommendation of the "Conseil Scientifique Régional du Patrimoine 405 Naturel" and the committee of the "Reserve Naturelle des Marais de Kaw-Roura" where the 406 experiment took place. This study was permitted after careful consideration of its impacts. We 407 also adhere to the "Guidelines for use of live amphibians and reptiles in field and laboratory 
research" by the Herpetological Animal Care and Use Committee (HACC) of the American

409 Society of Ichthyologists and Herpetologists. The study took place after the main breeding event

410 of the study species therefore minimizing the lasting effect on the population. Our experiment

411 attracted several species to the sound source during the playback, but it did not trigger breeding

412 and the animals dispersed after the playback. Any potential disturbance to other fauna by the

413 playback, the noise due to the generator powering the speakers, and the presence of the

414 experimenters in the area lasted for three hours each night, was temporary and localized to small

415 areas. The manipulation of animals was limited to very brief displacements of a few meters. The

416 study required digging of holes (16 per pond, 4 stations of 4 traps) for pitfall traps but these were

417 refilled at the end of the experiment.

418 


\section{References}

420

421 Aichinger, M. (1987). Annual activity patterns of anurans in a seasonal neotropical 422 environment. Oecologia 71(4), 583-592.

423

424

425

426

427

428

429

430

431

432

433

434

435

436

437

438

439

440

441

Akaike, H. (1973). Information theory and an extension of the maximum likelihood principle. In: B. N. Petrov \& F. Caski (Eds.) Proceedings of the Second International Symposium on Information Theory (pp. 267-281). Budapest: Akademiai Kiado.

Alford, R. A. (1999). Ecology: resource use, competition, and predation. In: R. W. McDiarmid, \& R. Altig (Eds.) Tadpoles: The Biology of Anuran Larvae (pp. 240-278). Chicago: University of Chicago Press.

Altig, R., \& Johnston, G.F. (1989). Guilds of anuran larvae: relationships among developmental modes, morphologies, and habitats. Herpetological Monographs 1, 81109.

Amézquita, A., Flechas, S.V., Lima, A.P., Gasser, H., \& Hödl, W. (2011). Acoustic interference and recognition space within a complex assemblage of dendrobatid frogs. Proceedings of the National Academy of Sciences 108(41), 17058-17063.

Bates, D., Mächler, M., Bolker, B., \& Walker, S. (2014). Fitting linear mixed-effects models using lme4. Journal of Statistical Software 67, 1-48.

Bee, M. A. (2007). Selective phonotaxis by male wood frogs (Rana sylvatica) to the sound of a chorus. Behavioral Ecology and Sociobiology 61(6), 955-966.

Bernal, X. E., Rand, A. S., \& Ryan, M. J.. (2007). Sex differences in response to nonconspecific advertisement calls: receiver permissiveness in male and female túngara frogs. Animal Behaviour 73(6), 955-964. 
Buxton, V. L., Ward, M. P., \& Sperry, J. H. (2015). Use of chorus sounds for location of breeding habitat in 2 species of anuran amphibians. Behavioral Ecology 26(4), 11111118.

Buxton, V. L., Ward, M. P., \& Sperry, J. H. (2018). Evaluation of conspecific attraction as a management tool across several species of anurans. Diversity 10(1), 6 .

Chang, C., Cheng, Y. C., \& Lin, S. M. (2018). Influence of conspecific and heterospecific cues on phonotaxis behavior in a polyandrous treefrog. Behavioral Ecology and Sociobiology 72(11), 179.

Christie, K., Schul, J., \& Feng, A. S. (2010). Phonotaxis to male's calls embedded within a chorus by female gray treefrogs, Hyla versicolor. Journal of Comparative Physiology

Danchin, E., Giraldeau, L. A., Valone, T. J., \& Wagner, R. H. (2004). Public information: from 454 nosy neighbors to cultural evolution. Science 305(5683), 487-491.

Diego-Rasilla, F. J., \& Luengo, R. M. (2004). Heterospecific call recognition and phonotaxis in the orientation behavior of the marbled newt, Triturus marmoratus. Behavioral Ecology and Sociobiology 55(6), 556-560.

Diego-Rasilla, F. J., \& Luengo, R. M. (2007). Acoustic orientation in the palmate newt, Lissotriton helveticus. Behavioral Ecology and Sociobiology 61(9), 1329-1335.

Ferguson, D. E. (1971). The sensory basis of orientation in amphibians. Annals of the New York Academy of Sciences 188, 30-36.

462 Forsman, J. T., Mönkkönen, M., Korpimäki, E., \& Thomson, R. L. (2012). Mammalian nest 463 predator feces as a cue in avian habitat selection decisions. Behavioral Ecology 24(1), 262-266. 
467 Gerhardt, H. C., \& Huber, F. (2002). Acoustic communication in insects and anurans: common problems and diverse solutions. Chicago, IL: University of Chicago Press.

Gerhardt, H. C., \& Klump, G. M. (1988). Phonotactic responses and selectivity of barking treefrogs (Hyla gratiosa) to chorus sounds. Journal of Comparative Physiology A 163(6):795-802.

Gerhardt HC, Schwartz JJ (1995) Interspecific interactions and species recognition. In: H. Heatwole \& B. K. Sullivan (Eds.). Amphibian Biology, vol 2. Social Behavior (pp 603-632). Surrey Beatty, Chipping Norton, UK.

Goodale, E., Beauchamp, G., Magrath, R. D., Nieh, J. C., \& Ruxton, G. D. (2010). Interspecific information transfer influences animal community structure. Trends in Ecology and Evolution 25(6), 354-361.

Gottsberger, B., \& Gruber, E. (2004). Temporal partitioning of reproductive activity in a neotropical anuran community. Journal of Tropical Ecology 20(3), 271-280.

Grafe, T.U., Döbler, S. \& Linsenmair, K.E., 2002. Frogs flee from the sound of fire. 269(1495), pp.999-1003.

Hartig, F. (2017). DHARMa: residual diagnostics for hierarchical (multi-level/mixed) regression models. $\mathrm{R}$ package version 0.1 .

Heusser, H. (1960). Über die Beziehungen der Erdkröte (Bufo bufo L.) zu ihrem Laichplatz II. Behaviour 16, 93-109.

Hödl, W. (1990). Reproductive diversity in Amazonian lowland frogs. Fortschritte der 488 Zoologie 38, 41-60.

Hothorn T, Bretz F, Westfall P (2008). "Simultaneous Inference in General Parametric Models.” Biometrical Journal, 50(3), 346-363. 
Inger, R. F., Voris, H. K., \& Frogner, K. J. (1986). Organization of a community of tadpoles in rain forest streams in Borneo. Journal of Tropical Ecology 2(3), 193-205.

Ishii, S., Kubokawa, K., Kikuchi, M., \& Nishio, H. (1995). Orientation of the toad Bufo japonicus toward the breeding pond. Zoological Science 12, 475-484.

James, M. S., Stockwell, M. P., Clulow, J., Clulow, S., \& Mahony, M. J. (2015). Investigating behaviour for conservation goals: Conspecific call playback can be used to alter amphibian distributions within ponds. Biological Conservation 192, 287-293.

Jenkins, C. N., Pimm, S. L., \& Joppa, L. N. (2013). Global patterns of terrestrial vertebrate diversity and conservation. Proceedings of the National Academy of Sciences 110(28), E2602-E2610.

Joly, P. (2019). Behavior in a changing landscape: using movement ecology to inform amphibian conservation. Frontiers in Ecology and Evolution 7, 155.

Larsen, O. N., \& Radford, C. (2018). Acoustic conditions affecting sound communication in air and underwater. In: H. Slabbekoorn, R. J Dooling, A. N. Popper, \& R. R. Fay Eds.). Effects of anthropogenic noise on Animals (pp. 109-144), New York: Springer New York.

Lillis, A., Eggleston, D. B., \& Bohnenstiehl D. R. (2013). Oyster larvae settle in response to habitat-associated underwater sounds. PLoS ONE 8, 1-10.

Lindén, A., \& Mäntyniemi, S. (2011). Using the negative binomial distribution to model overdispersion in ecological count data. Ecology 92(7), 1414-1421.

Madden, N., \& Jehle, R. (2017). Acoustic orientation in the great crested newt (Triturus cristatus). Amphibia-Reptilia 38, 57-65.

Magrath, R.D., Haff, T.M., Fallow, P.M. and Radford, A.N., 2015. Eavesdropping on heterospecific alarm calls: from mechanisms to consequences. Biological Reviews, 90(2), pp.560-586. 
516 Marty, C., \& Gaucher, P. (1999). Guide sonore des Amphibiens Anoures de Guyane. CD

517 audio. Mens: CEBA.

518 McGuire, B., Oli, M. K., \& Getz, L. L. (2009). Effects of conspecific and heterospecific

519 residents on patterns of immigration in two species of voles. Acta theriologica 54(4),

$520 \quad 321-332$.

521 Mönkkönen, M., Härdling, R., Forsman, J. T., \& Tuomi; J. (1999). Evolution of heterospecific

522 attraction: using other species as cues in habitat selection. Evolutionary Ecology 13(1),

$523 \quad 93-106$.

524 Mukhin, A., Chernetsov, N., \& Kishkinev, D. (2008). Acoustic information as a distant cue for 525 habitat recognition by nocturnally migrating passerines during landfall. Behavioral $526 \quad$ Ecology 19(4), 716-723.

527 Mullet, T. C., Farina, A., \& Gage, S. H. (2017). The acoustic habitat hypothesis: an 528 ecoacoustics perspective on species habitat selection. Biosemiotics 10, 319-336.

529 Oldham, R. S., \& Gerhardt, H. C. (1975). Behavioral isolating mechanisms of the treefrogs $530 \quad$ Hyla cinerea and H. gratiosa. Copeia 23, 223-231.

531 Pašukonis, A., Trenkwalder, K., Ringler, M., Ringler, E., Mangione, R., Steininger, J., 532 Warrington, I., \& Hödl, W. (2016). The significance of spatial memory for water 533 finding in a tadpole-transporting frog. Animal Behaviour 116, 89-98.

534 Penna, M., Pottstock, H. and Velasquez, N., 2005. Effect of natural and synthetic noise on 535 evoked vocal responses in a frog of the temperate austral forest. Animal Behaviour, $536 \quad 70(3)$, pp.639-651.

537 Phelps, S. M., Rand, A. S., \& Ryan, M. J. (2007). The mixed-species chorus as public 538 information: túngara frogs eavesdrop on a heterospecific. Behavioral Ecology 18(1), 539 108-114. 
540 Pittman, S. E., Osbourn, M. S., \& Semlitsch, R. D. (2014). Movement ecology of amphibians: a missing component for understanding population declines. Biological Conservation $169,44-53$.

543 Prado, C., Uetanabaro, M., \& Haddad, C. (2005). Breeding activity patterns, reproductive modes, and habitat use by anurans (Amphibia) in a seasonal environment in the Pantanal, Brazil. Amphibia-Reptilia 26(2), 211-221.

Pupin, F., Sacchi, R., Gentilli, A., Galeotti, P., \& Fasola, M. (2007). Discrimination of toad calls by smooth newts: support for the heterospecific attraction hypothesis. Animal

Reed, J. M., \& Dobson, A. P. (1993). Behavioural constraints and conservation biology: conspecific attraction and recruitment. Trends in Ecology and Evolution 8(7), 253256.

Robertson, J. G. (1986). Male territoriality, fighting and assessment of fighting ability in the Australian frog Uperoleia rugosa. Animal Behaviour 34(3), 763-772.

Rodrigues, D. J., Lima, A. P., Magnusson, W. E., \& Costa, F. R. 2010. Temporary pond

Ryan, M. J., \& Rand, A.S. (1993). Species recognition and sexual selection as a unitary problem in animal communication. Evolution 47(2), 647-657.

Ryan, M. J., Tuttle, M. D., \& Taft, L. K. (1981). The costs and benefits of frog chorusing behavior. Behavioral Ecology and Sociobiology 8(4), 273-278. communities: molecular identification, morphological characterisation, and ecological assignment. Zootaxa 4016(1), 1-11. 

information use is a process across time, space, and ecology, reaching heterospecifics. Ecology 88(7), 1622-1633.

Shoop, C. R. (1965). Orientation of Ambystoma maculatum: movements to and from breeding ponds. Science $149,558-559$.

Simmons AM (2013) "To Ear is Human, to Frogive is Divine”: Bob Capranica's legacy to auditory neuroethology. J Comp Physiol A 199:169-182

Simpson, S. D., Meekan, M., Montgomery, J., McCauley, R., \& Jeffs, A. (2005). Homeward Sound. Science 308, 221.

Sinsch, U. (1990). Migration and orientation in anuran amphibians. Ethology Ecology and Evolution 2(1), 65-79.

Sinsch, U. (2006). Orientation and navigation in Amphibia. Marine and Freshwater Behaviour and Physiology 39, 65-71.

Sinsch, U. (2014). Movement ecology of amphibians: from individual migratory behaviour to spatially structured populations in heterogeneous landscapes. Canadian Journal of Zoology 92(6), 491-502.

Slabbekoorn, H., \& Bouton, N. (2008). Soundscape orientation: a new field in need of sound investigation. Animal Behaviour 76(4), e5-e8.

Stamps, J. A. (1988). Conspecific attraction and aggregation in territorial species. American

Stanley, J. A., Radford, C. A., \& Jeffs, A. G. (2012). Location, location, location: finding a suitable home among the noise. Proceedings of the Royal Society B: Biological Sciences 279, $3622-3631$. 
Swanson, E. M., Tekmen, S. M., \& Bee, M. A. (2007). Do female frogs exploit inadvertent social information to locate breeding aggregations? Canadian Journal of Zoology 85, $921-932$

Thomson, R. L., Forsman, J. T., \& Mönkkönen, M. (2003). Positive interactions between migrant and resident birds: testing the heterospecific attraction hypothesis. Oecologia 134(3), 431-438.

Ulloa, J. S., Aubin, T., Llusia, D., Courtois, E. A., Fouquet, A., Gaucher, P., Pavoine, S., \& Sueur, J. (2019). Explosive breeding in tropical anurans: environmental triggers, community composition and acoustic structure. BMC Evolutionary Biology 19, 28.

Vélez, A., Schwartz, J.J. and Bee, M.A., 2013. Anuran acoustic signal perception in noisy environments. In Animal communication and noise (pp. 133-185). Springer, Berlin, Heidelberg.

Wells, K. D. (1977). The social behaviour of anuran amphibians. Animal Behaviour 25, 666693.

Wells, K. D. (2007). The ecology and behavior of amphibians. University of Chicago Press.

Wogel, H., Abrunhosa, P. A., \& Pombal, J. P. (2006(. Chorus organization of the leaf-frog Phyllomedusa rohdei (Anura, Hylidae). Herpetological Journal 16(1), 21-27.

Wollerman, L., \& Wiley, R. H. (2002). Background noise from a natural chorus alters female discrimination of male calls in a Neotropical frog. Animal Behaviour 63(1), 15-22.

Wrona, F. J.,\& Dixon, R. J. (1991). Group size and predation risk: a field analysis of encounter and dilution effects. American Naturalist 137(2), 186-201. 